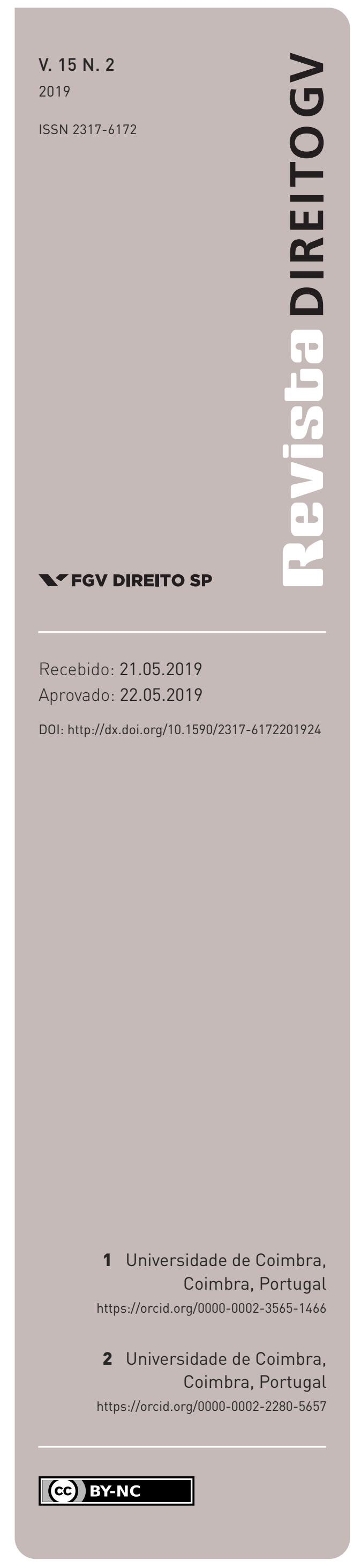

\title{
A extradição de Portugal para o Brasil de cidadãos portugueses naturalizados
}

\author{
NATURALIZED PORTUGUESE CITIZENS' EXTRADITION FROM PORTUGAL TO BRAZIL
}

\author{
J.J. Gomes Canotilho' e Nuno Brandão ${ }^{2}$
}

\section{Resumo}

A extradição de nacionais constitui matéria prevista e regulada tanto na Constituição brasileira, como na Constituição portuguesa. Dos comandos constitucionais que a regulam resulta para o Brasil uma proibição absoluta de extradição dos seus cidadãos natos, daí derivando para Portugal, em virtude do princípio constitucional da reciprocidade, uma proibição de extradição para o Brasil de portugueses originários. Fica, por isso, em aberto, apenas a questão da extradição dos cidadãos que tenham obtido a nacionalidade por naturalização. É essa a temática objecto deste estudo, que avalia a possibilidade de o Estado português responder positivamente a pedidos de extradição de portugueses naturalizados que the sejam dirigidos pelo Brasil. No tratamento do problema, convoca-se o princípio da reciprocidade, a Convenção de Extradição da CPLP, a Convenção de Viena sobre o Direito dos Tratados e os princípios da igualdade, universalidade e ordem pública, concluindose pela impossibilidade de extradição de portugueses naturalizados.

\section{Palavras-chave}

Extradição; cidadãos naturalizados; princípio da reciprocidade; princípio da igualdade; ordem pública.

\begin{abstract}
The extradition of nationals is a matter foreseen and regulated both in the Brazilian Constitution and in the Portuguese Constitution. From the constitutional commands that govern it, Brazil has an absolute prohibition on the extradition of its native citizens, thus deriving to Portugal a prohibition on extradition of native Portuguese to Brazil, due to the constitutional principle of reciprocity. This leaves open the question of the extradition of citizens who have obtained citizenship by naturalization. This is the subject of this study, which assesses the possibility of the Portuguese State to respond positively to requests for the extradition of naturalized Portuguese coming from Brazil. In addressing the problem, the principle of reciprocity, the CPLP Extradition Convention, the Vienna Convention on the Law of Treaties and the principles of equality, universality and public order are taken into account, and it is concluded that extradition of naturalized Portuguese is not allowed.
\end{abstract}

\section{Keywords}

Extradition; naturalized citizens; principle of reciprocity; principle of equality; public order. 


\section{O PROBLEMA}

1. A relação entre Portugal e Brasil é, em boa medida, marcada pelos fluxos dos seus cidadãos de um país para o outro. Esta realidade, de séculos, leva a que, não raro, os Estados português e brasileiro solicitem entre si cooperação judiciária com vista à extradição de cidadãos portugueses e brasileiros que se encontram no Estado requerido por crimes cometidos no território do Estado requerente.

A generalidade desses pedidos não suscita problemas ou dificuldades de maior.

Nenhum obstáculo de monta será oponível à extradição para o Brasil de cidadãos brasileiros que se encontrem em Portugal relativamente a crimes praticados naquele país. E o mesmo se poderá entender no caso inverso, de extradição para Portugal, pelo Brasil, de portugueses que hajam cometido crimes em território português e que, entretanto, se hajam deslocado para o Brasil.

Por seu turno, a extradição de cidadãos originários do Estado requerido será sempre inviável.

O Brasil não extradita cidadãos brasileiros de origem, os chamados brasileiros natos. Proibição que resulta de forma directa e absoluta do inciso LI do artigo $5 .^{\circ}$, da Constituição da República Federativa do Brasil (CRFB): "nenhum brasileiro será extraditado, salvo o naturalizado, em caso de crime comum, praticado antes da naturalização, ou de comprovado envolvimento em tráfico ilícito de entorpecentes e drogas afins, na forma da lei”. ${ }^{1}$

A Constituição da República Portuguesa (CRP) veda igualmente a extradição de portugueses. Não o faz, porém, como veremos infra de forma desenvolvida, em termos tão extremados como os da Constituição brasileira. Com efeito, o artigo $33 .^{\circ},{ }^{\circ} .^{\circ} 3$, da CRP, proíbe o Estado português de extraditar portugueses, mas abre espaço à extradição de nacionais em determinados casos: "A extradição de cidadãos portugueses do território nacional só é admitida, em condições de reciprocidade estabelecidas em convenção internacional, nos casos de terrorismo e de criminalidade internacional organizada, e desde que a ordem jurídica do Estado requisitante consagre garantias de um processo justo e equitativo". Esta exigência de reciprocidade que se estabelece neste $\mathrm{n} . .^{\circ} 3$ do artigo $33 .^{\circ}$ da CRP implica a impossibilidade de extradição para o Brasil de cidadãos portugueses originários: se o Brasil não extradita para Portugal brasileiros natos (artigo $5 .^{\circ}$, inc. LI, da CRFB), então Portugal não pode extraditar para o Brasil portugueses natos.

Como verdadeiramente problemático sobra, assim, apenas o caso em que o pedido de extradição incida sobre um cidadão do Estado requerido com o estatuto de cidadão naturalizado.

1 Assim, o HC 83.113 QO (rel. Min. Celso de Mello, j. 26-6-2003): "O brasileiro nato, quaisquer que sejam as circunstâncias e a natureza do delito, não pode ser extraditado, pelo Brasil, a pedido de Governo estrangeiro, pois a Constituição da República, em cláusula que não comporta exceção, impede, em caráter absoluto, a efetivação da entrega extradicional daquele que é titular, seja pelo critério do jus soli, seja pelo critério do jus sanguinis, de nacionalidade brasileira primária ou originária”. 
É precisamente sobre esta situação que este estudo se deterá, procurando avaliar se é ou não admissível - e em caso afirmativo, sob que condições - a extradição para o Brasil, pelo Estado português, de cidadãos portugueses naturalizados. ${ }^{2}$

Problema que, como vem de se ver, convoca a comparação das normas deônticas plasmadas na Constituição portuguesa (artigo 33. ${ }^{\circ}$, n. ${ }^{\circ} 3$ ) e na Constituição do Brasil (artigo 5. ${ }^{\circ}$, inc. LI). Mas não só: os processos de extradição convocam uma metódica combinatória das estruturas normativo-constitucionais com convenções internacionais e actos legislativos de especial incidência nos problemas de extradição e de combate à criminalidade (Tratado de Amizade, Cooperação e Consulta entre Portugal e Brasil, Lei de Cooperação Judiciária Internacional em Matéria Penal, Convenção de Extradição entre Estados Membros da CPLP, Convenção das Nações Unidas contra o Crime Organizado Transnacional, etc.). Exige-se, assim, uma tessitura hermenêutica de perímetros fácticos de âmbito juridicamente protegidos típicos de regimes internormativos, que, como se verá nos desenvolvimentos argumentativos subsequentes, acabará por revelar que no problema estão em jogo princípios básicos da juridicidade estatal: o princípio da igualdade e o princípio da reciprocidade.

\section{O QUADro CONSTITUCIONAL GERAL DA EXTRADiÇÃO DE CIDADÃOS PORTUGUESES}

2. Como se viu, quando um pedido de extradição apresentado ao Estado português recaia sobre um cidadão português, seja ele originário ou naturalizado, deverá esse requerimento ser de imediato reconduzido ao plano constitucional, mais especificamente ao já mencionado artigo 33. ${ }^{\circ}$, n. ${ }^{\circ}$ 3, da CRP. Embora as fontes normativas directamente reguladoras de um determinado

2 Esta precisa questão foi recentemente objecto de apreciação e discussão nos tribunais portugueses, no âmbito do pedido de extradição de Raul Schmidt Felippe Junior - cidadão nascido no Brasil e que obteve a cidadania portuguesa, por naturalização, em 2011 -, formulado pelo Estado brasileiro ao Estado português no contexto da operação Lava Jato. O processo correu termos, sob o n. 483/16.7YRLSB, primeiro, no Tribunal da Relação de Lisboa (Acórdão de 07-12-2016) e, depois, no Supremo Tribunal de Justiça (Acórdão de 07-09-2017, http:/ /www.dgsi.pt. Acesso em: 16 jun. 2019). Tomada decisão a favor da extradição, o visado dirigiu-se ao Tribunal Constitucional, que, todavia, por razões formais, não chegou a conhecer o mérito das questões de constitucionalidade suscitadas no recurso interposto (cfr. a Decisão Sumária do TC n. 679/2017 e o Acórdão do TC n. 824/2017, este último publicado em http: / /www.tribunaconstitucional.pt).

A extradição, inicialmente deferida, acabou por ser rejeitada, em maio de 2018, com fundamento na circunstância de o visado ter entretanto adquirido o estatuto de cidadão português originário (cfr. despacho do Tribunal da Relação de Lisboa de 24-05-2018, disponível em https://www.conjur.com.br/dl/extradicao-raul.pdf. Acesso em: 16 jun. 2019). 
pedido de extradição sejam, em geral, de natureza convencional e, subsidiariamente, legal (em especial, a Lei n. ${ }^{\circ}$ 144/99, de 31/8, relativa à Cooperação Judiciária Internacional em Matéria Penal), questões há em que a própria Constituição chama a si a concreta definição normativa dos termos em que poderá proceder-se à extradição (cfr. artigo 33. ${ }^{\circ}$, n. ${ }^{\text {os }} 3,4$ e 6$) .^{3}$ É o caso, entre outros, da extradição de cidadãos portugueses do território nacional.

Dada a sua imediata aplicabilidade (artigo $18 .^{\circ}, \mathrm{n} .^{\circ} 1$, da CRP), será, assim, à luz da norma constante do n. 3 do artigo $33 .^{\circ}$ da CRP que, prima facie, deverão ser apreciados e decididos os pedidos de extradição de cidadãos portugueses que se encontrem em território nacional dirigidos ao Estado português. Faltando no caso de espécie algum dos pressupostos de que esse preceito constitucional faz depender a admissibilidade da extradição de portugueses, o Estado português estará proibido de cooperar com o Estado requerente através da concessão da extradição, existindo uma obrigação constitucional de recusa de extradição.

Com efeito, a Constituição portuguesa mantém a regra ${ }^{4}$ de que o Estado português não extradita os seus nacionais, deste modo garantindo aos cidadãos portugueses o direito (subjectivo) fundamental ${ }^{5}$ à não extradição do território português. Só a título de excepção, e sob apertados pressupostos por si definidos, admite a Constituição que este autêntico direito de defesa (Abwehrrecht) do cidadão português face ao Estado seja restringido. ${ }^{6}$

À semelhança do que sucede na generalidade dos países de direito romano-germânico ${ }^{7}$ e em conjugação com a aplicabilidade da lei penal nacional com base no princípio da nacionalidade activa, ${ }^{8}$ a regra da não extradição de nacionais constitui uma tradição do sistema jurídico português, só relativizada com a revisão constitucional de 1997 . Até então, o n. ${ }^{\circ} 1$ do artigo 33. ${ }^{\circ}$ da CRP estabelecia que "não são admitidas a extradição e a expulsão de cidadãos portugueses do território nacional”, passando depois a Constituição a admitir, no n. 3 daquele artigo 33..$^{\circ}$, na redacção que lhe foi dada pela Lei Constitucional n. ${ }^{\circ} 1 / 97$, a extradição de portugueses, nos termos já referidos.

O fundamento para a proibição que continua a subsistir como regra é o dever de protecção dos cidadãos portugueses que impende sobre o Estado português. ${ }^{9}$ Implicando a extradição do

3 CANOTILHO; MOREIRA, 2007, Art. 33. , V. e ss.

$4 \quad$ No sentido a que alude ALEXY, 1986, p. 71 e ss.

$5 \quad$ CANOTILHO, 2003, p. 407 e s.

6 CANOTIlHO; MOREIRA, 2007, Art. 33. ․, V. Cfr. ainda COSTA, 2019a, p. 780 e ss.

7 BLAKESLEY, 1991, p. 451 e ss., apresentando também, em contraponto, a tradição dos países de common law, que, via de regra, admitem a extradição dos seus nacionais.

8 FIGUEIREDO DIAS, 2007, 9. Cap., § 19.

$9 \quad$ Neste sentido, pela doutrina actualmente maioritária, COSTA, 2014, p. 54 e s. Para outros fundamentos historicamente aduzidos em favor da máxima da não extradição de nacionais (v.g., a tutela do princípio do juiz 
nacional a transferência coerciva do território pátrio para um país estrangeiro, com sacrifício, portanto, do seu direito fundamental à liberdade ambulatória, e com a sua sujeição ao poder punitivo penal de um Estado estrangeiro, justifica-se que a protecção que o Estado português está obrigado a dispensar aos cidadãos portugueses se manifeste numa proibição de princípio da sua entrega ao Estado requerente. Daí não decorrerá, em regra, a impunidade do facto criminoso objecto do pedido de extradição, porquanto, em caso de recusa, recairá sobre o Estado português um dever de submeter o visado ao procedimento criminal respectivo ou à sanção que lhe haja sido aplicada, em cumprimento do princípio de direito internacional dedere aut judicare, expressamente plasmado na legislação portuguesa (cfr. artigo 32. ${ }^{\circ}$, n. ${ }^{\circ}$ 5, da Lei n. ${ }^{\circ} 144 / 99$ e artigo 5. ${ }^{\circ}$, n. ${ }^{\circ} 1$, al. e), do Código Penal).

Radicando a regra da não extradição de nacionais no dever estadual de protecção dos cidadãos portugueses, compreende-se que a sua limitação, por seu turno fundada em exigências político-criminais de maximização da eficiência da perseguição penal de certos fenómenos criminais de dimensão internacional e no reforço dos laços de cooperação interestadual também no plano criminal, seja constitucionalmente rodeada de especiais cautelas. Deverá, concretamente, assentar numa relação de confiança institucional entre Estados, materializada numa exigência de reciprocidade pactuada em convenção internacional; terá de circunscrever-se a crimes de especial gravidade; e não poderá prescindir, atento o dever de protecção do extraditando nacional a que o Estado português se encontra obrigado, de uma circunstanciada ponderação sobre o processo penal que aguarda o cidadão português caso seja extraditado, só se admitindo a cooperação com o Estado estrangeiro se, objectiva e fundadamente, puder considerar-se que tal processo será justo e equitativo.

Estes cuidados foram assumidos pelo legislador constitucional na revisão constitucional de 1997, projectando-se na previsão, no n. 3 do artigo $33 .^{\circ}$ da CRP, de uma tríplice exigência constitucional em matéria de extradição de portugueses: "(1) reciprocidade de tratamento por parte do Estado requerente estabelecida em convenção internacional; (2) prática de crimes de excepcional gravidade (terrorismo e criminalidade internacional organizada); (3) exigência de garantias de um processo justo e equitativo por parte da ordem jurídica do Estado requisitante". ${ }^{10}$ Assegurados estes pressupostos, a Constituição não se oporá, em princípio, à extradição de um cidadão português. Extradição que, em todo o caso, terá sempre de subordinar-se ao primado da Constituição, não só, naturalmente, perante a lei ordinária, como também face ao direito convencional. ${ }^{11}$ De modo que a extradição só será admissível

\footnotetext{
$\cdots$

10 CANOTILHO; MOREIRA, 2007, Art. 33. ${ }^{\circ}, \mathrm{V}$.

natural, a falta de confiança num tratamento justo do visado pelo Estado requisitante ou a desvantagem em responder perante um processo tramitado numa língua estrangeira), cfr. WILLIAMS, 1991, p. 260 e ss. 
se as normas convencionais e/ou legais em que se pretenda fundá-la não contrariarem o ordenamento constitucional português.

Sendo este o enquadramento constitucional reclamado por um qualquer pedido de extradição dirigido ao Estado português que vise um cidadão nacional, é à sua luz que deverão ser apreciados os pedidos dirigidos ao Estado português pela República Federativa do Brasil para extradição de cidadãos portugueses naturalizados que se encontrem em território luso.

Em tal apreciação será indiferente se a pessoa visada já era ou não portuguesa à data da prática do crime motivador do pedido de extradição, uma vez que o artigo $33 .^{\circ}$, n $^{\circ} 3$, da CRP é aplicável independentemente do momento da aquisição da nacionalidade portuguesa. ${ }^{12}$ Significa isto que esta norma constitucional é aplicável não só a indivíduos já portadores da nacionalidade portuguesa aquando do cometimento do crime que justifica o pedido, como também a indivíduos que a hajam adquirido só depois da prática do crime, mas antes de tomada a decisão sobre o requerimento de extradição apresentado perante o Estado português. Neste sentido depõe, aliás, o disposto no n. ${ }^{\circ} 6$ do artigo 32. ${ }^{\circ}$ da Lei n. ${ }^{\circ}$ 144/99: "A qualidade de nacional é apreciada no momento em que seja tomada a decisão sobre a extradição”.

\section{A EXIGÊNCIA CONSTITUCIONAL DE RECIPROCIDADE ESTABELECIDA EM CONVENÇÃO INTERNACIONAL}

\section{A) O PRINCÍPIO DA RECIPROCIDADE}

3. Um inarredável pressuposto constitucional da extradição de um cidadão português é que tal extradição se realize em condições de reciprocidade estabelecidas em convenção internacional (artigo 33. ${ }^{\circ}, \mathrm{n} .^{\circ}$ 3, da CRP).

Constituindo a reciprocidade uma trave-mestra da cooperação judiciária internacional em matéria penal que o Estado português aceita prestar, ${ }^{13}$ nada mais natural do que erigi-la a condição indispensável e inderrogáve $1^{14}$ de uma eventual extradição quando em causa esteja um cidadão nacional. Na sua vertente clássica, do princípio da reciprocidade decorrerá que,

12 Na doutrina, COSTA, 2014, p. 55, e na jurisprudência o Acórdão do Tribunal da Relação de Lisboa de 17-11-2011 (Proc. n. ${ }^{\circ}$ 759/11.0YRLSB-3, http://www.dgsi.pt. Acesso em: 16 jun. 2019).

13 Cfr. o artigo 4. ${ }^{\circ},{ }^{\circ}{ }^{\circ} 1$, da Lei n. ${ }^{\circ} 144 / 99$ - "A cooperação internacional em matéria penal regulada no presente diploma releva do princípio da reciprocidade" -, não obstante a erosão a que a exigência de reciprocidade tem estado exposta nas últimas décadas: vd. ZIMMERMANN, 2004, p. 390 e ss.

14 Aos pedidos de extradição de portugueses é inaplicável o disposto no n. ${ }^{\circ} 3$ do artigo $4 .^{\circ}$ da Lei n. ${ }^{\circ}$ 144/99. 
em princípio, só poderão extraditar-se portugueses para o Estado requisitante se num caso similar esse Estado aceitasse extraditar para Portugal um cidadão seu nacional. Nesse sentido, o objecto do pedido de extradição há-de ser um tal que, a priori e em abstracto, poderá essa forma de cooperação considerar-se admissível seja qual for o Estado que ocupe a posição de requerente ou de requerido.

Não é só, porém, nesta última direcção, tributária da tradicional pretensão de fazer valer um desígnio de igualdade dos Estados (soberanos) intervenientes, que a reciprocidade releva, nomeadamente, quando é elevada a pressuposto da limitação de um direito fundamental, como se verifica no n. ${ }^{\circ} 3$ do artigo $33 .^{\circ}$ da Constituição portuguesa. Esta jusfundamentalização do princípio da reciprocidade ${ }^{15}$ tem um significado de restrição ao exercício do poder de extradição de que o Estado se arroga, para protecção do extraditando, no caso, um cidadão nacional. Deste modo, converte-se em "sinónimo de um mínimo de confiança mútua"16 na probidade do comportamento do Estado contraparte no seu relacionamento com o extraditando. Só se essa confiança existir, mais precisamente, a confiança de que o Estado requisitante respeitará a dignidade pessoal do extraditando cidadão português e não restringirá ilegitimamente os direitos fundamentais de que este é titular, estará reunida uma primeira condição para que o Estado português possa desobrigar-se da regra de proibição de extradição desse cidadão, fundada, como vimos, no dever de protecção dos cidadãos nacionais que sobre ele incide.

4. Em geral, o princípio da reciprocidade materializa-se por uma de duas vias: ${ }^{17}$ ou mediante prévia celebração de uma convenção internacional entre os Estados intervenientes, caso em que, por regra, as condições para a concretização da extradição serão as mesmas para todos e, como tal, reciprocamente exigíveis; ou através de uma pontual prestação de garantia de reciprocidade, como a que, no ordenamento português, se prevê no n. ${ }^{\circ} 2$ do artigo $4 .^{\circ}$ da Lei ${ }^{\circ}{ }^{\circ} 144 / 99$.

Considerando o disposto no n. ${ }^{\circ} 3$ do artigo $33 .^{\circ}$ da CRP, tratando-se da extradição de cidadãos portugueses do território português requerida ao Estado português, as condições de reciprocidade devem imperativamente constar de convenção internacional celebrada com o Estado requisitante. Convenção que, aquando da formalização do pedido de extradição do cidadão nacional, deve i) encontrar-se em vigor em ambos os ordenamentos jurídicos, ii) ser aplicável aos factos penalmente relevantes em relação aos quais se requer a extradição e iii) admitir como possível a extradição de pessoas suas nacionais.

Sobre esta tendência, ROVIRA, 2005, p. 189 e ss.

16 ROVIRA, 2005, p. 190.

17 COSTA, 2014, p. 79 e s. 
Actualmente, os pedidos de extradição formulados entre os Estados português e brasileiro abrigam-se na Convenção de Extradição entre os Estados Membros da Comunidade dos Países de Língua Portuguesa (doravante, Convenção de Extradição da CPLP), designadamente, no seu artigo $4 .^{\circ}$, al. a), que estabelece a facultatividade da recusa de extradição no caso de a pessoa reclamada ser nacional do Estado requerido. Porém, como procuraremos esclarecer de seguida, a Convenção de Extradição da CPLP não é susceptível de abranger todos os casos de pedidos de extradição de portugueses naturalizados dirigidos pelo Brasil a Portugal. Quando tal suceda, faltará uma condição essencial para viabilizar a extradição de nacionais estabelecida pelo artigo $33 .^{\circ}, \mathrm{n} .^{\circ} 3$, da CRP.

\section{B) A vigência da Convenção de Extradição da CPLP em Portugal e no Brasil}

5. Para que uma dada convenção internacional possa estribar a extradição pelo Estado português de uma pessoa portuguesa é necessário que, no momento da apresentação do pedido de extradição, a mesma se encontre em vigor em ambos os Estados que compõem a relação extradicional em apreço, o português e o requisitante. Não basta, como é óbvio, que a convenção haja sido assinada por esses Estados. É ainda absolutamente imprescindível que em cada um deles se mostre completo e concluído o processo constitucionalmente definido para que a convenção possa qualificar-se como vigente em relação a cada um. ${ }^{18}$ E vigente tanto no plano internacional, como no do direito interno.

Estando aqui em causa a vigência da Convenção de Extradição da CPLP em Portugal e no Brasil, assinada por ambos os Estados em 23-11-2005, vejamos então a partir de quando entrou ela em vigor, internacional e internamente, em cada um deles.

No caso de Portugal, a Convenção de Extradição da CPLP foi aprovada em 18-07-2008 pela Assembleia da República: Resolução da AR n. ${ }^{\circ}$ 49/2008, publicada em Diário da República em 15-09-2008. Nessa mesma data foi igualmente publicado o Decreto do Presidente da República n. ${ }^{\circ}$ 67/2008, que ratificou a Convenção. De acordo com o Aviso n. ${ }^{\circ}$ 183/2011 do Ministério dos Negócios Estrangeiros português, ${ }^{19}$ este instrumento de ratificação foi depositado junto do Secretariado Executivo da CPLP em 01-02-2010, considerando-se, por isso, nos termos do seu artigo $24 .^{\circ},{ }^{\circ}{ }^{\circ} 3$, que a Convenção entrou em vigor para Portugal no dia 01-03-2010. Desde esta data, portanto, a Convenção de Extradição da CPLP constitui base convencional para que o Estado português extradite cidadãos seus nacionais para outro Estado membro da CPLP.

Sem prejuízo de requisitos adicionais de atribuição de vigência constantes da própria convenção (cfr., v. g. , o artigo $24 .^{\circ}$, n. ${ }^{\text {os }} 2$ e 3, da Convenção de Extradição da CPLP).

Diário da República, I Série, de 11-08-2011, p. 4252 (http://www.dre.pt. Acesso em: 16 jun. 2019). 
O Congresso Nacional da República Federativa do Brasil aprovou o texto da Convenção de Extradição da CPLP através do Decreto Legislativo n. ${ }^{\circ} 45$, de $2009 .{ }^{20}$ Esta aprovação foi depositada pelo Estado brasileiro junto do Secretariado Executivo da CPLP em 01-06-2009, data em que entrou em vigor para a República Federativa do Brasil no plano jurídico externo.

Isto mesmo foi afirmado pelo Decreto Presidencial n. ${ }^{\circ}$ 7.935, de 19-02-2013, que procedeu à promulgação da Convenção de Extradição da CPLP e assim lhe atribuiu vigência também no plano do direito interno. ${ }^{21} \mathrm{~A}$ entrada em vigor da Convenção no plano jurídico interno brasileiro ocorreu no dia 20-02-2013, data em que aquele Decreto Presidencial foi publicado no Diário Oficial da União. ${ }^{22-23}$

Esta diferenciada atribuição de vigência, internacional e interna, para o Estado brasileiro das convenções internacionais de que é parte decorre do sistema instituído pela Constituição brasileira nesta matéria, sendo pacífica e unanimemente reconhecida pelos poderes legislativo, ${ }^{24}$ executivo ${ }^{25}$ e judiciário ${ }^{26}$ e pela doutrina. ${ }^{27}$ Com efeito, enquanto a aprovação das convenções internacionais é da competência do Congresso Nacional (artigo 49. ${ }^{\circ}$, inciso I, da CRFB), ${ }^{28}$ sendo suficiente para obrigar o Estado brasileiro no plano das relações externas com os demais Estados parte da convenção internacional em apreço (vigência internacional); a sua ratificação e promulgação cabe ao poder executivo, designadamente, ao Presidente da República (artigo 84. ${ }^{\circ}$, inciso IV, da CRFB) ${ }^{29}$ Só após esta promulgação, por decreto presidencial, a convenção é publicada no Diário Oficial da União, sendo que só a partir deste momento

Diário Oficial da União, Secção 1, n. ${ }^{\circ}$ 61, de 31-03-2009, p. 2.

21 "Considerando que o Acordo entrou em vigor para a República Federativa do Brasil, no plano jurídico externo, em $1^{\circ}$ de junho de 2009” (itálico nosso). Diário Oficial da União, Secção 1, n. ${ }^{\circ}$ 34, de 20-02-2013, p. 28. De acordo com o artigo 3..$^{\circ}$ do Decreto Presidencial n. ${ }^{\circ}$ 7.935, de 19-02-2013, o "Decreto entra em vigor na data de sua publicação".

24 Cfr. a informação da Secretaria da Informação Legislativa do Senado Federal relativa ao Decreto Legislativo n. ${ }^{\circ}$ 45, de 2009: “O texto do ato internacional aprovado por este Decreto Legislativo só será aplicável em território brasileiro a partir da sua promulgação pelo Poder Executivo”.

Cfr. o já citado 2. ${ }^{\circ}$ considerando do Decreto Presidencial n. ${ }^{\circ}$ 7.935, de 19-02-2013: "Considerando que o Acordo entrou em vigor para a República Federativa do Brasil, no plano jurídico externo, em $1^{\circ}$ de junho de 2009”. Cfr. o Acórdão do plenário do Supremo Tribunal Federal, tirado por unanimidade em 17-06-1998 (Agravo reg. em carta rogatória n. ${ }^{\circ}$ 8.279-4 República Argentina). Por todos, MELLO, 2000, p. 214-230, REZEK, 2011, p. 102 e ss., e GABSCH, 2010, p. 52 e s.

28 MELLO, 2000, p. 224 e ss.

29 Ementa do Ac. do Supremo Tribunal Federal (STF) brasileiro de 17-06-1998 (Agravo reg. em carta rogatória n. ${ }^{\circ}$ 8.279-4 República Argentina), p. 2: “A recepção dos tratados internacionais em geral e dos acordos 
poderá adquirir vigência também no plano interno, e assim obrigar as autoridades judiciárias e administrativas.

Na palavra de Celso de Mello, "os efeitos da promulgação consistem em: a) tornar o tratado executório no plano interno e b) 'constatar a regularidade do processo legislativo', isto é, o Executivo constata a existência de uma norma obrigatória (tratado) para o Estado. No Brasil a promulgação é feita por decreto do Presidente da República, onde é ordenada a execução do tratado, cujo texto aí figura e é publicado no Diário Oficial. (...) O importante é a executoriedade do tratado e esta só é possivel, no plano interno, com a publicação que leva ao conhecimento de todos a existência daquela norma internacional. Entretanto, no âmbito internacional ela já é obrigatória antes da publicação. A publicação é condição essencial para o tratado ser aplicado no âmbito interno". 30

Neste quadro, como sem dificuldade logo se pode inferir, as autoridades judiciárias brasileiras só podem admitir a prestação de cooperação judiciária em nome do Estado brasileiro com base em determinada convenção internacional depois de esta se tornar vigente no ordenamento interno brasileiro, mediante promulgação por decreto presidencial e publicação no Diário Oficial. Isto mesmo foi decidido, por unanimidade do plenário, pelo Supremo Tribunal Federal brasileiro no acórdão de 17-06-1998 (relator Celso de Mello), no qual se recusou um pedido de auxílio judiciário formulado pela Argentina ao Brasil com fundamento na circunstância de a convenção invocada para essa prestação de auxílio não ter sido objecto de promulgação pelo Presidente da República do Brasil, apesar de já aprovada pelo Congresso Nacional. Fazendo notar que, em virtude de imposição constitucional, a promulgação presidencial constitui condição insuprível da executoriedade interna de uma qualquer convenção internacional, o STF entendeu que "de jure constituto, (...) enquanto não se concluir o ciclo da sua transposição, para o direito interno, os tratados internacionais e os acordos comunitários, além de não poderem ser invocados, desde logo, pelos particulares, no que se refere aos direitos e obrigações neles fundados (princípio do efeito directo), também não poderão ser aplicados, imediatamente, no âmbito doméstico do Estado brasileiro (postulado da aplicabilidade imediata)" 31

celebrados pelo Brasil no âmbito do Mercosul depende, para efeito de sua ulterior execução no plano interno, de uma sucessão causal e ordenada de atos revestidos de caráter político-jurídico, assim definidos: (a) aprovação, pelo Congresso Nacional, mediante decreto legislativo, de tais convenções; (b) ratificação desses atos internacionais, pelo Chefe de Estado, mediante depósito do respetivo instrumento; (c) promulgação de tais acordos ou tratados, pelo Presidente da República, mediante decreto, em ordem a viabilizar a produção dos seguintes efeitos básicos, essenciais à sua vigência doméstica: (1) publicação oficial do texto do tratado e (2) executoriedade do ato de direito internacional público, que passa, então - e somente então - a vincular e a obrigar no plano do direito positivo interno".

30 MELLO, 2000, p. 228 e s. (itálicos nossos).

31 Cit, Agravo reg. em carta rogatória n. ${ }^{\circ}$ 8.279-4 República Argentina. p. 21. Nesta referência ao efeito 
Se é indubitável que a Convenção de Extradição da CPLP se tornou vigente no ordenamento interno brasileiro em 20-02-2013,32 é igualmente inequívoco que só a partir dessa data passou a verificar-se o pressuposto da reciprocidade estabelecida em convenção internacional previsto pelo n. ${ }^{\circ} 3$ do artigo 33. ${ }^{\circ}$ da Constituição portuguesa para que o Estado português extradite para o Brasil cidadãos portugueses com base naquela Convenção. É que até aí, dada a falta de executoriedade interna dessa Convenção no ordenamento brasileiro, estaria o Estado brasileiro impedido de extraditar para Portugal cidadãos (naturalizados) brasileiros.

Temos, pois, como seguro que, para efeitos do disposto no artigo $33 .^{\circ}, \mathrm{n} .^{\circ} 3$, da CRP, a Convenção de Extradição da CPLP passou a poder fundar pedidos de extradição do Estado brasileiro ao Estado português a partir de 20-02-2013, data em que, encontrando-se já em vigor em Portugal, passou a estar em vigor também na ordem jurídica interna brasileira. Assim sendo, e à partida, desde aquela data de 20-02-2013 que a Convenção de Extradição da CPLP constitui título constitucionalmente válido para sustentar pedidos de extradição que a República Federativa do Brasil dirija ao Estado português (e vice-versa).

\section{c) Os crimes abrangidos Pela Convenção de Extradição da CPLP}

6. Isto posto, importa, em todo o caso, ponderar em relação a que factos de natureza penal poderá admitir-se a extradição de um português naturalizado para o Brasil, em condições de reciprocidade, fundada na Convenção de Extradição da CPLP.

Em nosso modo de ver - e abstraindo por ora de outros eventuais obstáculos constitucionais, convencionais ou legais susceptíveis de implicar a recusa da extradição -, estando a Convenção de Extradição da CPLP simultaneamente em vigor nos ordenamentos jurídicos português e brasileiro desde 20-02-2013, é susceptível de aplicar-se a factos penalmente relevantes cometidos por portugueses ou brasileiros a partir dessa data, no âmbito de pedidos de extradição formulados pelos Estados brasileiro e português, respectivamente. Âmbito de aplicação que decorre da normal aplicabilidade ex nunc dos actos normativos, que abrange as convenções internacionais.

O mesmo já não poderá, todavia, entender-se em relação a factos penalmente relevantes praticados antes de se iniciar a vigência da Convenção de Extradição da CPLP nos ordenamentos

directo e à aplicabilidade directa dos tratados, o STF contrapõe expressamente o regime da Constituição brasileira ao disposto no n. ${ }^{\circ} 3$ do artigo $8 .^{\circ}$ da Constituição portuguesa, assinalada a divergência existente entre ambos (cfr. p. 20 e s.).

32 Não se afigura, por isso, correcta a informação constante do Aviso n. ${ }^{\circ}$ 183/2011 do Ministério dos Negócios Estrangeiros português de que "a Convenção já se encontra em vigor (...) para a República Federativa do Brasil desde 1 de Junho de 2009”. 
jurídicos português e brasileiro, isto é, quanto a crimes anteriores a 20-02-2013. ${ }^{33}$ A eventual aplicação dessa Convenção a factos inscritos nesse período temporal corresponderia a uma sua aplicação retroactiva, em frontal violação da proibição do princípio da não retroactividade dos tratados instituído pelo artigo 28. ${ }^{\circ}$ da Convenção de Viena sobre o Direito dos Tratados (doravante, Convenção de Viena), feita em 23-05-1969. Preceito que, de resto, mais não faz do que expressar uma máxima (preexistente) ${ }^{\mathbf{3 4}}$ de não retroactividade há muito reconhecida como princípio geral de direito internacional, correspondendo tanto a uma regra de direito consuetudinário internacional, como a um princípio geral de direito. ${ }^{35}$

A Convenção de Viena aplica-se aos tratados concluídos entre Estados (artigo 1. ${ }^{\circ}$ ) e tem como partes, ${ }^{36}$ entre muitos outros, o Estado português e o Estado brasileiro. Vigora no ordenamento jurídico português desde $07-03-2004 ;^{37}$ e no brasileiro, tanto no plano externo como no interno, desde 15-12-2009. ${ }^{38}$ Vigência que em cada um dos países precedeu a entrada em vigor da Convenção de Extradição da CPLP (como vimos, 01-03-2010 em Portugal e 20-022013 no Brasil).

Sob a epígrafe "Não retroactividade dos tratados", determina o artigo 28. da Convenção de Viena que "salvo se o contrário resultar do tratado ou tenha sido de outro modo estabelecido, as disposições de um tratado não vinculam uma Parte no que se refere a um acto ou facto anterior ou a qualquer situação que tenha deixado de existir à data da entrada em vigor do tratado relativamente a essa Parte". ${ }^{39}$ A norma tem como pano de fundo a clássica distinção

33 Em direcção divergente, vd. COSTA, 2019b, p. 5 e ss., p. 349, p. 449 e ss., acentuando a diferença entre o direito penal substantivo e o direito da extradição e sustentando que "o tempo verbal do direito da extradição é o tempo presente”, no sentido de que - pelo menos, de uma perpectiva de direito a constituir - as condições de admissibilidade da extradição deverão em princípio ser aferidas por referência ao momento da tomada de decisão do pedido.

$34 \quad$ KOTZUR, 2014, p. 167.

35 ODENDAHL, 2012, Article 28, n. ${ }^{\circ}$ m. 5, e KOTZUR, 2014, p. 156 e ss. e p. 161 e ss.

No sentido previsto na definição da alínea g) do n. ${ }^{\circ} 1$ do artigo 2. ${ }^{\circ}$ da própria Convenção: “g) 'Parte’ designa um Estado que consentiu em ficar vinculado pelo tratado e relativamente ao qual o tratado se encontra em vigor”.

37 Cfr. a Resolução da Assembleia da República n. ${ }^{\circ}$ 67/2003, de 7/8; o Decreto do Presidente da República n. ${ }^{\circ}$ 46/2003, de 7/8; e o Aviso do MNE n. ${ }^{\circ} 27 / 2004$ (Diário da República, I Série, de 03-04-2004, p. 2136 - http://www.dre.pt. Acesso em: 16 jun. 2019).

38 Cfr. o Decreto do Presidente da República n. ${ }^{\circ}$ 7.030, de 14-12-2009, publicado no Diário Oficial da União, Secção 1, n. ${ }^{\circ}$ 239, de 15-12-2009, p. 59, cujo artigo 3. ${ }^{\circ}$ determinou a sua entrada em vigor na data da sua publicação.

Na versão oficial em língua inglesa, o preceito tem a seguinte redacção: "Unless a different intention appears from the treaty or is otherwise established, its provisions do not bind a party in relation to any act or fact which took 
de direito internacional público entre facta praeterita, facta pendentia e facta futura, ${ }^{\mathbf{4 0}}$ tomando clara posição no sentido de que, em princípio, um Estado não poderá aplicar um tratado em que é parte a actos ou factos anteriores à entrada em vigor desse tratado na sua ordem jurídica.

É esse significado de inaplicabilidade que pacífica e unanimemente se atribui ao segmento normativo "as disposições de um tratado não vinculam uma Parte" ${ }^{41}$ constante do preceito. Não está aí em causa propriamente uma contraposição entre obrigações e direitos decorrentes de disposições de um tratado, mas antes um propósito de regulação do âmbito temporal de aplicação dos tratados. ${ }^{42}$ Assim, de acordo com o artigo 28. ${ }^{\circ}$ da Convenção de Viena, em regra, salvo se o contrário resultar do tratado ou tenha sido de outro modo estabelecido, um tratado só é aplicável aos actos e factos posteriores ao da sua entrada em vigor, encontrando-se, portanto, vedada a sua aplicação retroactiva aos facta praeterita e à parte pretérita dos facta pendentia. ${ }^{43}$

Esta proibição de princípio da retroactividade dos tratados vale, naturalmente, para as convenções internacionais em matéria de extradição. Tendo estas como propósito viabilizar e regular a transferência de um indivíduo de um Estado para outro, a fim de aí ser submetido a um processo penal ou cumprir uma pena criminal já aplicada por determinado crime, será por referência ao momento da prática da conduta ${ }^{44}$ que terá consubstanciado tal crime que deverá avaliar-se a aplicabilidade de determinada convenção internacional ao pedido de extradição em apreço. Com efeito, dada a inextricável relação entre a extradição e o crime que a poderá fundar, é óbvio que, no domínio extradicional, os $\operatorname{actos}^{45}$ a que o artigo $28 .^{\circ}$ da

place or any situation which ceased to exist before the date of the entry into force of the treaty with respect to that party”. E na francesa: “A moins qu'une intention différente ne ressorte du traité ou ne soit par ailleurs établie, les dispositions d'un traité ne lient pas une partie en ce qui concerne un acte ou fait antérieur à la date d'entrée en vigueur dece traité au regard de cette partie ou une situation qui avait cessé d'exister à cette date".

40 BLECKMANN, 1973, p. 46 e s.

41 Em inglês, "its provisions do not bind a party"; e em francês "les dispositions d'un traité ne lient pas une partie”.

42 Assim, expressamente e sem nota de quaisquer vozes em sentido contrário, BLECKMANN, 1973, p. 42 e s., ODENDAHL, 2012, Article 28, n. ${ }^{\circ}$ m. 12 e ss., e KOTZUR, 2014, p. 166 e ss.

43 BLECKMANN, 1973, p. 46 e s.

44 Cfr. o artigo $3 .^{\circ}$ do $\mathrm{CP}$ português, que, em consonância com o princípio constitucional da legalidade criminal (artigo 29..$^{\circ}$, n. ${ }^{o s} 1,3$ e 4, da CRP), situa no momento da acção (e não do da eventual produção de um resultado típico ou extratípico) o tempus delicti relevante para a determinação da lei temporalmente aplicável - vd. FIGUEIREDO DIAS, 2007, 8. ${ }^{\circ}$ Cap., § 32 e ss.

45 No sentido de que a locução "actos" constante do artigo 28. ${ }^{\circ}$ tem o significado de comportamentos imputáveis a sujeitos capazes de acção e a expressão "factos" se refere a circunstâncias que não podem ser reconduzidas a um comportamento (v. g., emissões, eventos naturais, acidentes danosos), BLECKMANN, 1973, p. 43 e s. 
Convenção de Viena se refere são os actos penalmente relevantes sobre os quais versa o concreto pedido de extradição apresentado ao abrigo de determinado tratado.

Esta compreensão de que, em sede de extradição fundada em tratado, a proibição de retroactividade prescrita pelo artigo 28. ${ }^{\circ}$ da Convenção de Viena obsta a que tal forma de cooperação judiciária possa ser prestada, com base no tratado, quanto a crimes cometidos antes da entrada em vigor desse tratado, é expressa não apenas pela doutrina, como também pelos tribunais de diversas jurisdições.

Nesse sentido pronunciou-se, em 2012, o Tribunal Internacional de Justiça no caso Bélgica vs. Senegal, em relação a uma imputação de uma violação pelo Senegal da obrigação de instauração de processo criminal por actos de tortura, constante do artigo $7 .^{\circ},{ }^{\circ}{ }^{\circ} 1$, da Convenção contra a Tortura. ${ }^{46}$ Mediante invocação do artigo $28 .^{\circ}$ da Convenção de Viena, considerou o TIJ que essa Convenção só seria aplicável no ordenamento senegalês relativamente a crimes cometidos após a entrada em vigor da Convenção no Senegal, motivo pelo qual concluiu não ter o Senegal violado o dever de promoção processual penal instituído por aquele artigo $7^{\circ}, \mathrm{n} .^{\circ} 1$, da Convenção quanto aos crimes praticados em momento anterior a essa entrada em vigor.

Também o Supremo Tribunal Federal brasileiro manifestou já o entendimento, quando confrontado com objecção à extradição fundada na anterioridade dos delitos em apreço face ao tratado em que se fundamentou o pedido de extradição, de que será possível "a aplicação retroactiva de tratado de extradição, desde que (...) haja expressa previsão pactuada pelos Estados celebrantes". 47 Desta forma, embora não tenha excluído a admissibilidade de um funcionamento retroactivo de um tratado de extradição, designadamente, em relação a condutas criminosas anteriores à da sua entrada em vigor, o STF, colocando a questão no quadro normativo do artigo 28. ${ }^{\circ}$ da Convenção de Viena, considerou que tal retroactividade da aplicação do tratado só seria legítima se expressamente acordada pelos Estados envolvidos.

7. Sendo seguro, em face do artigo $28 .^{\circ}$ da Convenção de Viena, que, salvo se o próprio tratado previr a sua aplicação retroactiva, o Estado português não está autorizado a aplicar um

46 Acórdão de 20-7-2012, in: Questions relating to the Obligation to Prosecute or Extradite (Belgium v. Senegal), Judgment, I.C.J. Reports 2012, n. ${ }^{o}$ m. 96 e ss. - http: / /www.icj-cij.org/docket/files/144/17064.pdf. Acesso em: 16 jun. 2019.

47 Decisão do ministro Celso de Mello, de 18-02-2016 (PPE 769/DF) (itálico nosso), no sentido da admissibilidade da extradição pela razão de o tratado em questão, celebrado entre o Brasil e a República Popular da China (promulgado pelo Decreto n. ${ }^{\circ} 8.431 / 2015$ ), admitir expressamente a sua aplicação "mesmo se os delitos pelos quais os pedidos [de extradição] forem apresentados tenham ocorrido antes de sua entrada em vigência” (artigo 22. ${ }^{\circ}$, n. ${ }^{\circ}$ 3). Cfr. http: / / www.stf.jus.br/arquivo/cms/noticiaNoticiaStf/anexo/ PPE769.pdf. Acesso em: 16 jun. 2019. 
tratado de extradição de que seja parte a crimes anteriores ao da sua entrada em vigor, vejamos quais as implicações deste dado normativo sobre o problema da extradição de portugueses naturalizados. Questão que não pode deixar de ser articulada com a exigência constitucional de que tal extradição se faça em condições de reciprocidade estabelecidas em convenção internacional (artigo 33..$^{\circ}$ n. ${ }^{\circ}$, da CRP).

7.1. Como vimos já, o postulado da reciprocidade imposto pelo artigo $33 .^{\circ}$, n. $^{\circ} 3$, da CRP deve materializar-se através de uma convenção internacional que admita a extradição de nacionais dos Estados parte e que se encontre em vigor em ambos os Estados da relação extradicional no momento em que o pedido de extradição é dirigido ao Estado português. Se a convenção estiver em vigor em Portugal, mas não no Estado requisitante, este não poderá extraditar com base nessa convenção. Por isso, nesse caso, se o Estado português extraditar o seu nacional para o Estado requerente fá-lo-á sem que estejam reunidas condições de reciprocidade estabelecidas em convenção internacional, o que implicará uma frontal violação do disposto no n. ${ }^{\circ} 3$ do artigo $33 .^{\circ}$ da Constituição portuguesa.

Esta mesma ordem de razão projecta-se, do mesmo passo, numa adicional exigência constitucional de aplicabilidade, no Estado português e no Estado requerente, da convenção internacional que sustenta o pedido de extradição ao período temporal em que o crime objecto desse pedido tiver sido praticado. Isto é, não basta que a convenção já esteja em vigor em ambos os Estados, é imperioso ainda que em ambos seja aplicável ao período em que se localiza o crime a que o pedido de extradição se refere. Pois se o não for, ficará irremediavelmente frustrada uma reciprocidade assente em tal convenção internacional.

Se, por exemplo, a convenção já entrou em vigor em Portugal, sendo assim aplicável aos crimes cometidos por portugueses no Estado contraparte, mas neste ainda não é vigente, não poderá este Estado extraditar para Portugal, com base nessa convenção, os seus nacionais pelos crimes que cometam no território português durante esse período. Impossibilidade de extradição quanto a esses crimes que subsistirá mesmo depois de a convenção entrar em vigor nesse Estado, dada a sua inaplicabilidade retroactiva, resultante do artigo $28 .^{\circ}$ da Convenção de Viena e/ ou do direito consuetudinário internacional, ao tempo anterior ao do seu início de vigência. E nessa medida, quanto a esse período, não poderá falar-se em reciprocidade. Consequentemente, será constitucionalmente inadmissível, à luz do artigo $33 .^{\circ}$, n. ${ }^{\circ} 3$, da CRP, a extradição de cidadãos portugueses por crimes cometidos nesse arco temporal.

Nestes termos, conjugado o artigo $33^{\circ}{ }^{\circ}, \mathrm{n} .^{\circ} 3$, da Constituição portuguesa com o artigo 28. ' da Convenção de Viena sobre o Direito dos Tratados, uma convenção internacional que admita a extradição dos nacionais dos Estados parte e não preveja a possibilidade da sua aplicação retroactiva a crimes cometidos em momento anterior ao da sua entrada em vigor nos ordenamentos desses Estados só pode fundar a extradição de um cidadão português concedida pelo Estado português a um Estado contraparte dessa convenção quanto aos crimes 
cometidos após essa convenção se encontrar simultaneamente em vigor em ambos os Estados, o português e o requerente.

7.2. Mobilizado este quadro normativo para o problema sob análise, da possibilidade de extradição para o Brasil de cidadãos portugueses naturalizados, encontrando-se a Convenção de Extradição da CPLP em vigor em Portugal e no Brasil somente a partir de 20-02-2013, só por crimes posteriores a essa data poderá Portugal extraditar cidadãos portugueses para o Brasil. ${ }^{48}$

Na realidade, nem do artigo 24. ${ }^{\circ}$ da Convenção de Extradição da CPLP, que define os termos da sua assinatura e da sua entrada em vigor, nem de uma sua qualquer outra disposição decorre, expressa ou sequer implicitamente, uma qualquer intenção dos Estados contratantes de afastarem o princípio da irretroactividade dos tratados. E por isso está vedada a sua aplicação retroactiva, desde logo por força do disposto no artigo 28. ${ }^{\circ}$ da Convenção de Viena, mas também do direito consuetudinário internacional.

Deste modo, não poderá o Brasil extraditar para Portugal, com base na Convenção de Extradição da CPLP, cidadãos brasileiros naturalizados por crimes cometidos em momento anterior à sua entrada em vigor no ordenamento interno brasileiro, 20-02-2013. Donde, reversamente, atenta a exigência de reciprocidade estabelecida em convenção internacional constante do artigo $33^{\circ}{ }^{\circ}$ n. ${ }^{\circ}$ 3, da CRP, está o Estado português proibido, pela própria Constituição, de lançar mão da Convenção de Extradição da CPLP para extraditar para o Brasil cidadãos portugueses quanto a crimes cometidos antes de 20-02-2013. Pois se, no presente, o Estado brasileiro não pode autorizar um pedido de extradição para Portugal de qualquer cidadão brasileiro naturalizado por crimes anteriores a 20-02-2013; 49 então, também não pode o Estado português extraditar cidadãos portugueses naturalizados por crimes cometidos antes dessa data. E não pode, justamente porque o artigo $33 .^{\circ},{ }^{\circ} .^{3}$, da CRP o proíbe, por falta de condições de reciprocidade.

Não subsiste, de resto, qualquer outro instrumento de direito convencional aplicável a crimes cometidos antes de 20-02-2013 susceptível de fundar a extradição de portugueses naturalizados para o Brasil. No quadro delimitado pelo artigo 33..$^{\circ}$ n. ${ }^{\circ}$, da CRP, a esses factos é ainda aplicável o Tratado de Extradição entre o Governo da República Portuguesa e o Governo

48 Concluindo em sentido contrário, a nosso ver, sem razão, o Acórdão do Supremo Tribunal de Justiça português de 07-09-2017 (Proc. n. ${ }^{\circ}$ 483/16.7YRLSB.S1, http://www.dgsi.pt. Acesso em: 16 jun. 2019).

49 Não o poderá fazer, porque, como concluímos já, tal implicaria uma aplicação retroactiva da Convenção de Extradição da CPLP que é proibida pelo direito brasileiro - cfr. de novo a Decisão do STF de 18-02-2016 (PPE 769/DF). 
da República Federativa do Brasil, ${ }^{\mathbf{5 0}}$ assinado em 07-05-1991 ${ }^{\mathbf{5 1}}$ e entrado em vigor na ordem jurídica portuguesa em 01-12-1994. ${ }^{52}$ Ora, o artigo 3. ${ }^{\circ}, \mathrm{n} .{ }^{\circ}$ 1, al. a), desse Tratado estabelecia expressamente que não haverá lugar a extradição no caso de ser a pessoa reclamada nacional da Parte requerida, pelo que não poderá constituir supedâneo para que o Estado português extradite cidadãos portugueses para o Brasil.

\section{IGUALDADE, UNIVERSALIDADE E ORDEM PÚBLICA}

8. Pelo exposto, o princípio da reciprocidade consagrado no artigo $33 .^{\circ}, \mathrm{n} .^{\circ} 3$, da CRP obsta à extradição para o Brasil de cidadãos portugueses naturalizados por crimes anteriores a 20-02-2013.

Ficam, assim, em aberto os casos em que os pedidos de extradição se refiram a crimes cometidos em momento posterior a essa data. Desses, haverá, não obstante, que excluir os crimes cometidos pelo nacional visado em momento posterior à aquisição da nacionalidade por naturaliza-

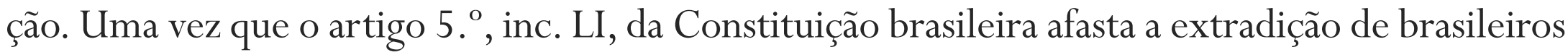
naturalizados relativamente a crimes praticados após a naturalização, em regra, ${ }^{\mathbf{5 3}}$ dada a necessidade de reciprocidade, Portugal não poderá extraditar para o Brasil portugueses naturalizados que hajam cometido crimes em solo brasileiro após a obtenção da nacionalidade portuguesa.

Tudo visto, parece, enfim, existir base constitucional e convencional para que o Estado português possa satisfazer os pedidos de extradição de cidadãos portugueses naturalizados que lhe sejam apresentados pelo Estado brasileiro relativamente a crimes por estes cometidos entre 20-022013 e a data em que se tornaram cidadãos portugueses mediante naturalização.

9. Resta, porém, saber se a concessão da extradição nessas situações não envolverá uma ofensa de normas constitucionais de outra ordem, justificando-se, por isso, a negação do pedido de cooperação judiciária recebido pelo Estado português.

Na direcção desta conclusão, BLECKMANN, 1973, p. 50: "Quando, de acordo com o artigo 28. ${ }^{\circ}$ [da Convenção de Viena], o novo tratado não seja aplicável aos facta praeterita, permanece aplicável o anterior regime. O artigo 28. ' determina, assim, por outras palavras, que o direito anterior se aplica aos facta praeterita”.

51 Cfr. a Resolução da Assembleia da República n. ${ }^{\circ}$ 5/94 (Diário da República, I Série, de 03-02-1994 http: / /www.dre.pt. Acesso em: 16 jun. 2019) e o Decreto do Presidente da República n. ${ }^{\circ}$ 3/94 (Diário da República, I Série, de 03-02-1994 - http://www.dre.pt. Acesso em: 16 jun. 2019).

52 Cfr. o Aviso do Ministério dos Negócios Estrangeiros n. $330 / 94$ (Diário da República, I Série, de 24-111994 - http://www.dre.pt. Acesso em: 16 jun. 2019).

53 Deverão, em todo o caso, ressalvar-se os crimes de tráfico ilícito de entorpecentes e drogas afins praticados após a naturalização, uma vez que o artigo $5 .^{\circ}$, inc. LI, da CRFB autoriza a extradição de brasileiros naturalizados por crimes desta natureza cometidos após a naturalização. 
Temos em mente, para sermos precisos, a centralidade normativa, em sede de processo de extradição, da contraposição entre cidadãos de origem e cidadãos naturalizados. Distinção que, embora nesta sede seja desconhecida da Constituição portuguesa, é feita pela Constituição brasileira (artigo 5. ${ }^{\circ}$, inc. LI), e que, por via do princípio da reciprocidade, poderá acabar por repercutir-se sobre as decisões de extradição a tomar pela República Portuguesa.

No fim da linha, em certas circunstâncias, um português será ou não extraditável para o Brasil consoante seja ou não português originário: se for, não pode ser extraditado; se não for, pode ser. Diferença de tratamento que, bem vistas as coisas, radica não no sistema constitucional português, mas no brasileiro. E que, por isso, obriga inevitavelmente a questionar a compatibilidade de uma tal solução com a ordem constitucional de valores portuguesa, estruturada, além do mais, sobre o princípio da igualdade.

Cumpre, deste modo, ponderar se deparamos ou não aqui com uma violação do princípio da igualdade, consagrado no artigo $13 .^{\circ}$ da CRP. O que implica a identificação dos objectos de referência da operação de igualdade: quem e o que é igual. Basicamente, os objectos de referência são dois: (i) espécies e modos de tratamento; (ii) as situações (pessoas) e os resultados.

\section{A) IgUALDADE DE TRATAMENTO}

10. Se a operação de igualdade mobiliza com a estrutura relacional tridimensional - relação entre, pelo menos, dois objectos e uma medida de comparação (tertium comparationis) -, então, no contexto do caso, deve considerar-se prima facie que os extraditandos no ordenamento jurídico-constitucional português e no ordenamento jurídico-constitucional brasileiro têm um tratamento de igual.

A igualdade de tratamento implica que, no momento do input, o "tratamento do tratamento" dos cidadãos portugueses e brasileiros operado nas leis fundamentais tem de conduzir a uma igualdade do status dos cidadãos alvo de pedido de extradição. Isso não implica, porém, que no fim da operação de igualdade (output), o resultado seja o de igualdade pressuposta no "tratamento do tratamento" constitucional.

Noutros termos, porventura mais incisivos: a operacionalidade da igualdade pode ter como resultado não uma igualdade, mas uma diferenciação - cidadãos de origem e cidadãos naturalizados - produtora de efeitos jurídicos cuja conformidade ou desconformidade com o âmbito juridicamente protegido deverá ser sujeito ao devido teste de constitucionalidade ou inconstitucionalidade.

\section{B) IGUALDADE NO CASO CONCRETO}

11. A transposição deste esquema de operacionalização para o problema sub judice pode iluminar melhor o que se acaba de escrever. A diferenciação entre "cidadãos originários" e "cidadãos naturalizados" conduz a que (i) no direito constitucional português todos os cidadãos 
portugueses poderão estar sujeitos a um processo de extradição formulado pela ordem jurídica brasileira enquanto (ii) no direito constitucional brasileiro só os cidadãos naturalizados poderão ser alvo de pedido de extradição impetrado pelas autoridades portuguesas competentes. Daqui resulta, como consequência, que a partir de um "tratamento do tratamento" constitucional de cidadãos sobre os quais recaem pedidos de extradição emergem resultados jurídicos radicalmente falhos de reciprocidade. Não se trata de censurar o esquema dicotómico do ordenamento constitucional brasileiro. Pretende-se, sim, afirmar com positividade e convicção que o tratamento unitário e igual dos cidadãos portugueses - sejam portugueses de origem, sejam portugueses naturalizados - é uma imposição da ordem pública constitucional portuguesa. ${ }^{\mathbf{5 4}}$

Na realidade, ao contrário das Constituições portuguesas anteriores, a Constituição da República Portuguesa de 1976 “não faz distinção entre cidadãos originários e cidadãos naturalizados, sendo, por isso, inconstitucional qualquer restrição de direitos fundamentais dos cidadãos portugueses não originários, a não ser que a Constituição expressamente a admita ou determine" ${ }^{55}$ Entre esses direitos fundamentais conta-se, naturalmente, o direito a não ser extraditado pelo Estado português para um país estrangeiro, para o qual não se prevê constitucionalmente uma susceptibilidade de restrição em função do estatuto de nacional originário ou naturalizado do cidadão visado.

\section{c) Proibição de discriminação}

12. O artigo $33^{\circ},{ }^{\circ} .^{\circ} 3$, combinatoriamente articulado com o artigo $13 .^{\circ}, \mathrm{n} .^{\circ} 2$, ambos da CRP, permite abranger as três garantias jurídico-subjectivas que estruturam hoje o princípio da igualdade: (1) direito à igualdade perante a lei; (2) direito à igualdade através da lei; e (3) proibição de discriminação.

Perante os "resultados" ou "efeito jurídico" a que nos conduziu a "igualdade de tratamento" e sua incidência no princípio da reciprocidade, justifica-se ainda a proibição de discriminação entre “cidadãos de origem” e "cidadãos naturalizados” em face da Constituição portuguesa. O pressuposto de aplicação do princípio da discriminação envolve, neste contexto, a comparabilidade de "status" e de "Tabestände". Em termos mais utilizados pela jurisprudência internacional, o pressuposto da "reciprocidade-igualdade-proibição de discriminação" aponta para "similar situated situation", “analogous situations", "relevantly similar situation”, "appropriate comparator group”, “wesentliche Gleicheit der Sachverhalt". O "tertium comparationis" da igualdade terá de reconduzir-se ao status de cidadania plena perante pedidos de extradição.

54 Para mais desenvolvimentos sobre a nossa compreensão da ideia de ordem pública neste domínio, cfr. CANOTILHO; BRANDÃO, 2016, n. ${ }^{\circ}$ 4000, p. 17 e ss. 
Não vale a pena retomar a "história" deste status na Constituição portuguesa. A proibição de extradição de cidadãos portugueses - de origem ou naturalizados - só admite excepção "nos casos de terrorismo e de criminalidade internacional organizada, e desde que a ordem jurídica do Estado requisitante consagre garantias de um processo justo e equitativo". O "tertium comparationis" - proibição, pura e simples, de extradição de cidadãos nacionais - indicia que à partida os cidadãos portugueses e os cidadãos brasileiros não estão em "situações análogas” ou numa "igualdade essencial de situação jurídica e jusfundamental”. A ordem pública portuguesa jusfundamentalmente assente na "universalidade de direitos", na "universalidade de direitos iguais" e na "proibição de discriminação de direitos em razão da origem” constitui, enfim, um limite intransponível à operacionalidade de pedidos de extradição ${ }^{56}$ de cidadãos portugueses naturalizados com que o Estado português seja confrontado. ${ }^{\mathbf{5 7}}$

\section{D) SÍNTESE CONCLUSIVA}

13. Verificamos, em suma e em conclusão, que o princípio da reciprocidade vertido no n. ${ }^{\circ} 3$ do artigo 33. ${ }^{\circ}$ da Constituição portuguesa induz o estabelecimento de uma relação de articulação com o artigo $5^{\circ}$, inciso LI, da Constituição brasileira, do qual resulta um output, no plano da ordem jurídica portuguesa, que quebra a igualdade de tratamento que o Estado português deve dispensar a todos os cidadãos portugueses, independentemente de serem originários ou naturalizados. Um output discriminatório que por não ser consentido pelo artigo $13 .^{\circ}, \mathrm{n}^{\text {os }} 1$ e 2, da Constituição portuguesa constitui obstáculo intransponível à extradição para o Brasil de cidadãos portugueses naturalizados.

\section{REFERÊNCIAS}

ALEXY, Robert. Theorie der Grundrechte, Frankfurt a. M.: Suhrkamp, 1986.

ALTWICKER, Tilmann. Menschenrechtlicher Gleichheitsschutze (International Equal Protection Law). Heidelberg/New York: Springer, 2011.

56 Cfr. ALTWICKER, 2011, p. 27 e ss. e p. 121 e ss. Aprofundando a diferença e a articulação entre esta igualdade e discriminação, cfr. MARTINS, 2010, p. 51 e ss.

57 Em direcção contrária, não reconhecendo a existência de tratamento discriminatório, mais uma vez, o Acórdão do Supremo Tribunal de Justiça de 07-09-2017 (Proc. n. ${ }^{\circ}$ 483/16.7YRLSB.S1). 
BLAKESLEY, Christopher L. The law of international extradition: a comparative study. Revue Internationale de Droit Pénal, v. 62, 1. ${ }^{\circ}$ e 2. ${ }^{\circ}$ trimestres, p. 381-468, 1991.

BLECKMANN, Albert. Die Nichtrückwirkung völkerrechtlicher Verträge. Kommentar zu Art. 28 der Wiener Vertragsrechtskonvention. Zeitschrift für ausländisches öffentliches Recht undVölkerrecht, v. 33, p. 38-55, 1973.

CANOTILHO, J. J. Gomes. Direito Constitucional e Teoria da Constituição, 7. a ed., Coimbra: Almedina, 2003.

CANOtilho, J. J. Gomes; MOREIRA, Vital. Constituição da República Portuguesa Anotada, I, 4. ${ }^{\text {a ed., }}$ Coimbra: Coimbra Editora, 2007.

CANOTILHO, J. J. Gomes; BRANDÃO, Nuno. Colaboração premiada e auxílio judiciário em matéria penal: a ordem pública como obstáculo à cooperação com a operação Lava Jato. Revista de Legislação e de Jurisprudência, n. ${ }^{\circ}$ 4000, p. 16-48, 2016.

COSTA, Miguel João. Dedere aut Judicare? A Decisão de Extraditar ou Julgar à Luz do Direito Português, Europeu e Internacional, Coimbra: Instituto Jurídico da FDUC, 2014.

COSTA, Miguel João. Policies of International Friendship in Judicial Cooperation in Criminal Matters: The Non-Extradition of Brazilian and Portuguese Nationals to Third States - A Comparison with EU Law. Revista Brasileira de Direito Processual Penal, vol. 5, n. ${ }^{\circ}$ 2, p. 773-817, mai./ago. 2019a.

COSTA, Miguel João. Extradition Law: Reviewing Grounds for Refusal from the Classic Paradigm to Mutual Recognition and Beyond. Leiden: Brill | Nijhoff, no prelo (2019b), gentilmente cedido pelo autor.

FIGUEIREDO DiAS, Jorge de. Direito Penal. Parte Geral, I, 2. a ed., Coimbra: Coimbra Editora, 2007.

GABSCH, Rodrigo d'Araujo. Aprovação de Tratados Internacionais pelo Brasil, FUNAG, 2010, p. 52 e s.

KOTZUR, Markus. Chapter 6: The temporal dimension: Non-retroactivity and its discontents. In: TAMS, Christian J.; TZANAKOPOULOS, Antonios; ZIMMERMANN, Andreas (orgs.), Research Handbook on the Law of Treaties, Edward Elgar, p. 153-185, 2014.

MARTINS, Ana Maria Guerra. A Igualdade e a Não Discriminação dos Nacionais de Estados Terceiros Legalmente Residentes na União Europeia - Da Origem da Integração Económica ao Fundamento na Dignidade do Ser Humano, Coimbra: Almedina, 2010. 
MELLO, Celso Albuquerque de. Curso de Direito Internacional Público, $1 .^{\circ}$ vol., $12 .^{a}$ ed., Rio de Janeiro: Renovar, 2000.

ODENDAHL, K. Article 28. In: DÖRR, Oliver; SCHMALENBACH, Kirsten (orgs.), Vienna Convention on the Law of Treaties, Berlin: Springer, 2012.

REZEK, Francisco. Direito Internacional Público. Curso Elementar, 13. a ed., São Paulo: Saraiva, 2011.

ROVIRA, Antonio. Extradición y Derechos Fundamentales, Cizur Menor Navarra:Thomson Civitas, 2005.

WILLIAMS, Sharon. Nationality, double jeopardy, prescription and the death sentence as bases for refusing extradition. Revue Internationale de Droit Pénal, v. 62 , 1. e e 2..$^{\circ}$ trimestres, p. 259-280, 1991.

ZIMMERMANN, Robert. La Coopération Judiciaire Internationale en Matière Pénale, 12. ${ }^{\mathrm{a}}$ ed., Bern: Staempfli, 2004.

\section{COMO CITAR ESTE ARTIGO:}

CANOTILHO, J.J. Gomes; BRANDÃO, Nuno. A extradição de Portugal para o Brasil de cidadãos portugueses naturalizados. Revista Direito GV, v. 15, n. 2, e1924. doi: http://dx.doi.org/ 10.1590/2317-6172201924.

\section{J.J. Gomes Canotilho}

Professor Catedrático da Faculdade de Direito da Universidade de Coimbra, Coimbra, Portugal.

jjcanotlafd.uc.pt

Nuno Brandão

Professor Auxiliar da Faculdade de Direito da Universidade de Coimbra, Coimbra, Portugal. nbrandaolafd.uc.pt 